\title{
Mechanical Properties of MEMS Materials
}

\author{
Zdravko Stanimirović and Ivanka Stanimirović \\ IRITEL A.D. \\ Republic of Serbia
}

\section{Introduction}

The performance of micro electronic and mechanical systems (MEMS) strongly depends on the mechanical properties of materials used. The evaluation of the mechanical properties of MEMS materials is indispensable for designing MEMS devices. Accurate values of mechanical properties (elastic properties, internal stress, strength, fatigue) are necessary for obtaining the optimum performances. For an example, elastic properties are necessary in prediction of the amount of deflection from an applied force and material strength sets device operational limits. Also, in view of reliability and life time requirements, mechanical characterization of MEMS materials becomes increasingly important. Small size of MEMS devices often leads to their usage in harsh environments, and good knowledge of mechanical properties may lead to elimination of some of the mechanical failure modes through proper material selection, design, fabrication and packaging processes. As the interest in MEMS grows, the demand for applicable data increases. Reliability, accuracy and repeatability of evaluation methods also became an issue. However, MEMS use materials such as silicon and many other thin films that are not fully characterized regarding their mechanical properties because they had not previously been considered as mechanical materials. The properties of thin films have so far been evaluated mostly to satisfy demands in semiconductor device research, but evaluations were mainly focused on the electrical properties, while investigations of mechanical properties were limited mainly to internal stresses. For that reason, the bulk properties were adopted whenever mechanical properties were needed, but with the growing application of thin films in various mechanical structures grew the need for better understanding of their mechanical and electromechanical properties. Therefore mechanical properties of thin films used in MEMS need to be accurately evaluated - they should be measured at the same scale as micro- and nanodevices since they differ from bulk material properties. Thin-film and bulk materials usually have different compositions, phase and microstructure and the formation process for thin films must be taken into account (deposition, thermal treatment, implantation and oxidation). Mechanical processing as the processing method for most bulk structures is in case of thin films substituted with photolithography and etching. Also, bulk and thin film have different surface finishing of processed structures. When size effect is concerned, one must have in mind that the ratio of surface area to the volume increases as dimensions of a device decrease. The dimensions of structures in MEMS devices range from submicrometers to millimetres and therefore the size effect in thin films is more sensitive than in bulk materials. Many measurement methods have been developed for evaluation of 
mechanical properties of thin films and various values have been measured (Ammaleh, 2003; Dual, 2004; Yi, 1999). Reported variations in measured values were large requiring extensive research in order to evaluate repeatability, accuracy and data reliability of various measurement methods for mechanical properties of MEMS materials. Therefore, development of international standards on MEMS materials and their properties measurement methods is one of the primary tasks when MEMS technology is in question. For that reason, this chapter intends to give an overview of basic test methods and mechanical properties of MEMS materials. Definitions of mechanical properties of interest are presented along with current test methods for MEMS materials. Also, a summary of mechanical properties of various MEMS materials is given. Measured material data for MEMS structural materials is obtained from the literature. Finally, the brief overview of the topic is presented in the last section, pointing out the necessity of standardization of testing procedures that would accelerate advances in MEMS technology.

\section{Mechanical properties}

MEMS devices use materials such as silicon and many other thin films. These materials had not previously been considered mechanical materials and for that reason are not fully characterized regarding their mechanical properties. The evaluation of the mechanical properties of electrical materials forming MEMS devices is needed to provide the engineering base for full exploitation of the MEMS technology. It is essential both from the aspect of MEMS device performances, as well as from the reliability aspect. Mechanical properties of interest fall into three general categories: elastic, inelastic, and strength. In order to predict the amount of deflection from the applied force, or vice versa, the elastic properties of MEMS materials must be known. Inelastic material properties are important for ductile materials, when deformed structure does not return to its initial state. When defining operational limits of MEMS device, the strength of the material must be known. The key factor in manufacturing reliable MEMS devices is good understanding of the relation between the material properties and its processing. When studying material properties, measured values should be independent of test method and the size of the specimen. However, when MEMS devices are in question, the size of the specimen may affect the measurements. For that reason an extensive process should be initiated in defining test methods with adequate sensibility and repeatability that would provide accurate values of mechanical properties.

\subsection{Elastic properties}

Elastic properties are directly related to the device performance. Young's modulus and Poisons ratio are basic elastic properties that govern the mechanical behavior. Since two independent mechanical properties are necessary for full definition of mechanical properties of MEMS materials, their properties can be accurately determined by measuring Young's modulus and Poisson's ratio. Young's modulus (E) is a measure of a material stiffness. It is the slope of the linear part of stress-strain $(\varepsilon-\sigma)$ curve of a material. Poisson's ratio is a measure of lateral expansion or contraction of a material when subjected to an axial stress within the elastic region. Load-deflection technique enables measuring E together with $\sigma$. The concept of this technique is shown in figure 1 using a circular membrane. The loaddeflection technique is easy to apply because the membrane is flat without load enabling 
easy load-deflection relationship measurement. The deflection of the membrane center $(\mathrm{d})$ is measured with the applied pressure $(\mathrm{P})$ across the membrane. Then, the pressure-deflection behavior of a circular membrane (Tsuchiya, 2008) is expressed by

$$
P=\frac{4 \sigma_{0} t}{a^{2}} d+\frac{8 E t}{3(1-v) a^{4}} d^{3},
$$

where $\mathrm{P}$ is the applied pressure, $\mathrm{d}$ is the center deflection, $a, \mathrm{t}, \mathrm{E}, \mathrm{o}_{0}$ and $v$ are the radius, thickness, Young's modulus and Poisons ratio of the circular membrane, respectively. As the equation shows, the range of Poison's ratio of materials is not wide and rough estimation of the ratio is acceptable using the bulk properties.
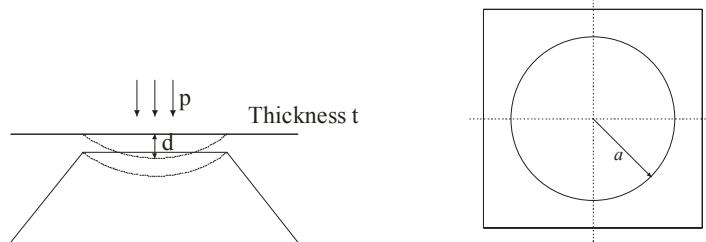

Fig. 1. The load-deflection technique for simultaneous $\mathrm{E}$ and $\sigma$ measurement

\subsection{Internal stress}

Internal stress $(\sigma)$, the strain generated in thin films on thick substrates, causes the deformation of the microstructure and occasionally destruction of the structure. It has two sources:

- thermal mismatch between a substrate and a thin film - extrinsic stress,

- microscopic structural change of a thin film (caused by chemical reactions, ion bombardment, absorption, adsorption etc.) - intrinsic stress.

In case of thin film compression the compressive stress is in question. Compressive stress is expressed as a negative value and it may cause buckling. In case of thin film expansion the tensile stress is in question. Tensile stress is expressed as a positive value and if excessive may lead to fracture of structures. According to Hooke's law, for isotropic materials under biaxial stress (such as thin films on substrates), internal stress is described by

$$
\sigma=\varepsilon E /(1-v)
$$

where $\varepsilon, \mathrm{E}$ and $v$ are the strain, Young's modulus and Poisson's ratio of the thin film, respectively.

As a micro fabricated test for strain measurement the beam buckling method is often used. In order to measure $\varepsilon$ of thin films the doubly supported beam shown in figure 2 is loaded by the internal stress. The preparation of pattern with incrementally increasing size enables determination of the critical length of the beam which causes buckling.

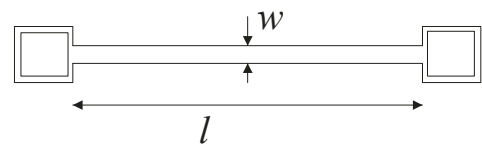

Fig. 2. Doubly supported beam structure 
The strain deduced from the buckling length of the beam (Tabata, 2006) is given as:

$$
\varepsilon=\frac{\pi^{2}}{3}\left(\frac{t}{l_{c}}\right)^{2},
$$

where $\varepsilon, t$ and $l_{c}$ are the strain, thickness of the thin film and the buckling length, respectively. In this case, the internal stress is assumed to be uniform along the thickness direction. In case of the stress distribution along the thickness direction, variation of $\varepsilon$ may cause vertical deflection of the cantilever beam.

\subsection{Strength}

The strength of a material determines how much force can be applied to a MEMS device. It needs to be evaluated in order to assure reliability of MEMS devices. Strength depends on the geometry, loading conditions as well as on material properties. As the useful measure for brittle materials, the fracture strength is defined as the normal stress at the beginning of fracture. The flexural strength is a measure of the ultimate strength of a specified beam in bending and it is related to specimen's size and shape. For inelastic materials, the yield strength is defined as a specific limiting deviation from initial linearity. The tensile strength is defined as a maximum stress the material can withstand before complete failure while the compressive strength is usually related to brittle materials.

\subsection{Fatigue}

MEMS devices are often exposed to cyclic or constant stress for a long time during operation. Such operational conditions may induce fatigue. Fatigue may be observed as change in elastic constants and plastic deformation leading to sensitivity changes and offset drift in MEMS devices. It may also be observed as the strength decrease that may lead to fracture and consequentially failure of the device. Fatigue behavior of a MEMS device also depends on its size, surface effects, effect of the environment such as humidity and temperature, resonant frequencies etc. In order to realize highly reliable MEMS device a detailed analysis of the fatigue behavior must be performed using accelerated life test method as well as life prediction method.

\section{Testing methods}

Minimum features in MEMS are usually of the order of $1 \mu \mathrm{m}$. Measuring mechanical properties of small MEMS specimens is difficult from the aspects of reliability, repeatability and accuracy of measurements. In order to measure mechanical properties of the MEMS device a specimen must be obtained and mounted. Since the microdevices are produced using deposition and etching processes a specimen must be produced by the same process used in device production. The following step is dimension measurement. The thicknesses of layers are controlled and measured by the manufacturer and lengths are sufficiently large to be measured by an optical microscope with required accuracy. However, the width of the specimen may cause the problem due to its small dimensions as well as imperfect definition of cross section that may cause uncertainty in the area. Therefore, possible measurement techniques include optical or scanning electron microscopy, interferometry, mechanical or optical profilometry. The next step in measuring mechanical properties of MEMS is the 
application of force/displacement resulting in deformation. This step is followed by force, displacement or strain measurements. Force and displacement measurements are based on tensile and bending tests or on usage of commercially available force and displacement transducers. When strain measurements are in question, it is preferable to measure strain directly on tensile specimens. It enables determination of the entire strain-stress curve from which the properties are obtained. The strain measurement technique known as interferometric strain/displacement gage is usually used apart from variety of other techniques that have not yet been applied to extensive studies of mechanical properties of MEMS. However, in most cases when MEMS materials are in question, direct methods for mechanical properties determination are not suitable. Instead, inverse methods are being used: a model is constructed of the test structure. After the force application and displacement measurements, elastic, inelastic or strength properties can be extracted from the model. Nevertheless, the variations in measured properties are large for both types of testing methods: direct and inverse. The source of variations is not established since there are too many differences among the properties measured by different methods. Obviously, the development of international standards for measuring the mechanical properties of MEMS materials will result in more accurate properties and reliable measurements.

\subsection{Tensile testing methods}

When tensile testing methods are concerned there are three arrangements that can be used. The first of them is specimen in a supporting frame. The tensile specimen is patterned onto the wafer surface and the gage section is exposed by etching the window in the back of the wafer. The specimen suspended across a rectangular frame enables convenient handling and testing. An example of specimen in a supporting frame is shown in figure 3.

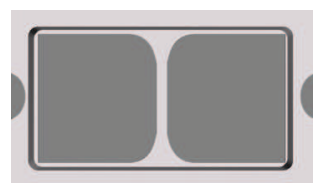

Fig. 3. Schematic of a silicon carbide tensile specimen in a silicon support frame

The second arrangement used in tensile testing is a specimen fixed at one end. At one end the test specimens fixed to the die while the other is connected to the test system. There is a variety of ways a specimen fixed at one end may be connected to a test system. A free end may be gripped by the electrostatic probe, glued to the force/displacement transducer, connected to the test system by the pin in case of ring shaped grip end, etc. An example of specimen fixed at one end is shown in figure 4.

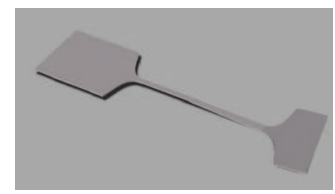

Fig. 4. Schematic of a tensile specimen fixed to the die at one end

The third arrangement used in tensile tests of MEMS materials is the freestanding specimen. This arrangement applies to small tensile specimens with submillimeter dimensions. The 
geometry commonly used in these tests is shown in figure 5. Microspecimens have grip ends that can be fitted into inserts in the grips of the test machine.

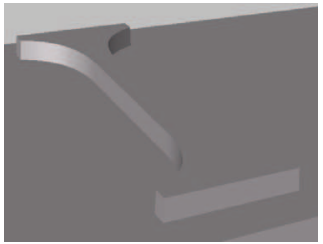

Fig. 5. Schematic of nickel free standing microspecimen on a silicon substrate

\subsection{Bend tests}

Similar to tensile testing methods, bend tests also use three arrangements. The first of them is out-of plane bending. Long, narrow and thin beams of the test material are being patterned on the substrate. The material under the cantilever beam is being etched away leaving the beam hanging freely over the edge. By applying the force as shown in figure 6 and measuring the force vs. deflection at the end or near the end of the beam, Young's modulus can be extracted.

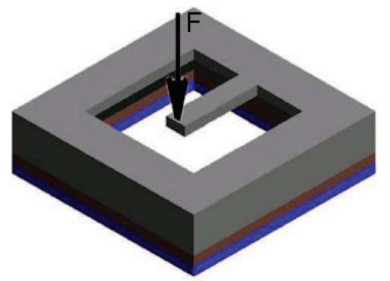

Fig. 6. Shematic of crystal silicon cantilever microbeam that can be used in out-of-plane bending test

The second arrangement used in bend tests is the beam with fixed ends - so called fixedfixed beam. The schematic of the most usually used on-chip structure is shown in figure 7 . Between the silicon substrate and polysilicon beam with clamped ends a voltage is applied pulling the beam down. The voltage that causes the beam to make contact is a measure of beam's stiffness.

The third arrangement used in bend testing of MEMS materials is in-plane bending (fig. 8). Test structure consisting of cantilever beams subjecting to in-plane bending may be used in fracture strain determination, crack growth and fracture toughness measurements, etc.

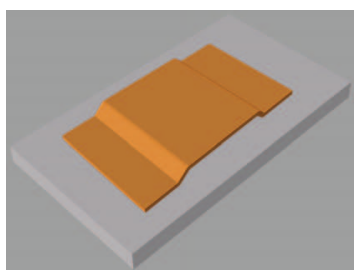

Fig. 7. Schematic of a polysilicon fixed-fixed beam on a silicon substrate 


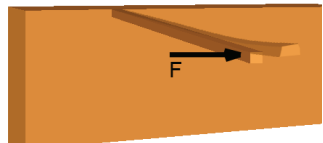

Fig. 8. Schematic of polysilicon cantilever beam subjected to in-plane bending

\subsection{Resonant structure tests}

Resonant structure tests are being used for determination of elastic properties of MEMS devices. Very small test structures used in these tests can be excited by capacitive comb drives which require only electrical contact making this approach suitable for on-chip testing. The most often used resonant structure concepts also include different in-plane resonant structures with a variety of easily modeled geometries as well as test structures based on arrays of cantilever beams fixed at one or both ends excited in different manners. As an illustration, in figure 9 a schematic of a in-plane resonant structure is shown.

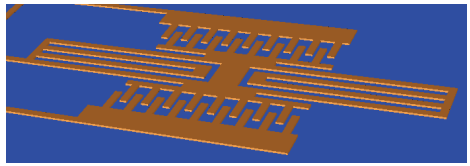

Fig. 9. Schematic of the in-plane resonant structure

\subsection{Bulge testing}

Bulge testing is also often called membrane testing. By etching the substrate material a thin membrane of test material is formed. The ideal architecture to achieve a direct tensile testing scheme involves a free standing membrane fixed at both ends (Espinosa, 2003) as shown in figure 10. When load is applied at the center of the membrane (usually using nanoindenter), a uniform stretch on the two halves of the thin membrane is achieved. In this manner the specimen's structural response is obtained as well as elastic behavior and residual stress state.

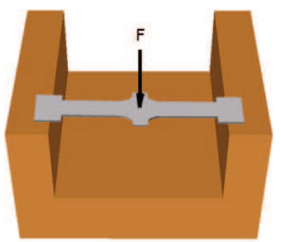

Fig. 10. Shematic of an Au membrane used in bulge testing

\subsection{Indentation tests}

In indentation tests a miniature and highly sensitive hardness tester (nanoindenter) is being used allowing force and displacement measurements. Penetration depths can be a few nanometers deep and automation permits multiple measurements and thus provides more reliable results. In such a manner Young's modulus and strength of various thin films can be obtained. As an illustration, a schematic of an indentation test is given in figure 11. 


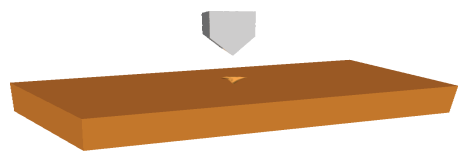

Fig. 11. Schematic of indentation test

\subsection{Other tests}

In order to measure forces in specimens the buckling test method can be used and if the specimen under pressure breaks the estimate of fracture strength can be obtained. This test method applied to test structures with different geometries and based on different MEMS materials can be used for determination of the Poisson's ratio, strain at fracture, residual strain in film, etc.

Another test method is the creep test. Creep tests are usually performed in cases when possibility of creep failure exists such as in thermally actuated MEMS devices resulting in a strain vs. time creep curve.

When torsion, one of important modes of deformation in some of MEMS devices, is concerned a few torsion tests have been developed enabling force and deflection measurements.

Fracture tests are of interest when brittle materials are in question. Fracture toughness is being measured using crack formation with a tip radius small relative to the specimen dimensions. Different positions and shapes of cracks are being used formed using different means such as etching, various types of indenters, etc.

When mechanical testing of MEMS materials is in question, standardization of test methods is a challenging task. A step forward in the direction of standardization may be implementation of "round robin" tests that should involve all relevant MEMS researchers in an effort to test common materials used in MEMS at their premises using the method of their choice. First such tests resulted in significant variation of results suggesting that further efforts should be made by involving more scientific resources.

\section{Data}

Polysilicon is the most frequently used MEMS material. In table 1 polysilicon mechanical properties data is given obtained by three types of tests: bulge, bend and tensile tests. Presented results show that polysilicon has Young's modulus mostly in the range between 160 and $180 \mathrm{GPa}$. Fracture strength depends on flaws in the material and performed tests do not necessarily lead to failure of the specimen. For that reason there are fewer entries for fracture strength and obtained results vary.

Mechanical properties of single-crystal silicon are given in table 2. Presented data is obtained using bending, tensile and indentation tests. The average values for the Young modulus ranged between 160 an $190 \mathrm{GPa}$.

In table 3 silicon-carbide mechanical properties data is presented. It is a promising MEMS material because of its superior properties (strength, stability, stiffness) and because of the current work on thin-film manufacturing processes few results are available obtained using bulge, indentation and bending tests.

Silicon nitride and silicon oxide mechanical properties data is presented in tables 4 and 5, respectively. Silicon nitride is used as an insulating layer in MEMS devices but it also has a potential as a structural material. On the other hand, silicon oxide because of its properties 
(low stiffness and strength) although included in MEMS devices does not have a potential of becoming a MEMS structural material.

There are few reports regarding the mechanical properties of metal thin films. Table 6 lists measured values of mechanical properties of metal materials commonly used in MEMS devices: gold, copper, aluminum and titanium. Metal films are tested using tensile testing in a free-standing manner. Results for electroplated nickel and nickel-iron MEMS materials are given in table 7. Presented results are obtained using tensile testing methods. Electroplated nickel and nickel-iron MEMS are usually manufactured by LIGA process. The microstructure and electrical properties of electroplated nickel are highly dependent on electroplating conditions while the properties of nickel-iron alloy depend on its

\begin{tabular}{|c|c|c|}
\hline Methods & $\begin{array}{c}\text { Young's Modulus } \\
\text { [GPa] }\end{array}$ & $\begin{array}{c}\text { Fracture Strength } \\
\text { [GPa] }\end{array}$ \\
\hline Bulge test & 160 & - \\
\hline Bulge test & $190-240$ & - \\
\hline Bulge test & $151-162$ & - \\
\hline Bulge test & $162 \pm 4$ & - \\
\hline Bending test & - & $2.11-2.77$ \\
\hline Bending test & 170 & - \\
\hline Bending test & $174 \pm 20$ & $2.8 \pm 0.5$ \\
\hline Bending test & $135 \pm 10$ & - \\
\hline Bending test & 198 & - \\
\hline Bending test & - & $3.2 \pm 0.3$ \\
\hline Bending test & - & $3.4 \pm 0.5$ \\
\hline Tensile test & $164-176$ & $2.86-3.37$ \\
\hline Tensile test & - & $0.57-0.77$ \\
\hline Tensile test & 140 & 0.7 \\
\hline Tensile test & $160-167$ & $1.08-1.25$ \\
\hline Tensile test & $169 \pm 6$ & $1.20 \pm 0.15$ \\
\hline Tensile test & 132 & - \\
\hline Tensile test & $140 \pm 14$ & $1.3 \pm 0.1$ \\
\hline Tensile test & $172 \pm 7$ & 1.76 \\
\hline Tensile test & 167 & $2.0-2.7$ \\
\hline Tensile test & 163 & $2.0-2.8$ \\
\hline Tensile test & - & $1.8-3.7$ \\
\hline Tensile test & $166 \pm 5$ & $1.0 \pm 0.1$ \\
\hline Tensile test & - & $4.27 \pm 0.61$ \\
\hline Tensile test & - & $2.85 \pm 0.40$ \\
\hline Tensile test & - & $3.23 \pm 0.25$ \\
\hline Tensile test & $158 \pm 8$ & $1.56 \pm 0.25$ \\
\hline Tensile test & - & $2.9 \pm 0.5$ \\
\hline Fixed ends test & 123 & - \\
\hline Fixed ends test & $171-176$ & - \\
\hline Fixed ends test & $149 \pm 10$ & - \\
\hline Fixed ends test & $178 \pm 3$ & - \\
\hline
\end{tabular}

Table 1. Polysilicon mechanical properties data (Sharpe, 2001) 
composition. Presented results show that these materials have high strength values (especially $\mathrm{Ni}-\mathrm{Fe}$ ) and therefore are suitable for application in actuators.

In table 8 diamond-like carbon mechanical properties data is presented. Diamond-like carbon is a MEMS material with excellent properties such as high stiffness and strength and low coefficient of friction. Presented results are obtained using three types of test methods: bending, buckling and tensile tests.

\begin{tabular}{|c|c|c|}
\hline Methods & $\begin{array}{c}\text { Young's Modulus } \\
{[\mathbf{G P a}]}\end{array}$ & $\begin{array}{c}\text { Fracture Strength } \\
{[\mathrm{GPa}]}\end{array}$ \\
\hline Bending test & $177 \pm 18$ & $2.0-4.3$ \\
\hline Bending test & 163 & $>3.4$ \\
\hline Bending test & $122 \pm 2$ & - \\
\hline Bending test & $173 \pm 13$ & - \\
\hline Bending test & - & $0.7-3.0$ \\
\hline Bending test & $165 \pm 20$ & $2-8$ \\
\hline Bending test & - & $2-6$ \\
\hline Bending test & 169.9 & $0.5-17$ \\
\hline Tensile test & 147 & $0.26-0.82$ \\
\hline Tensile test & $125-180$ & $1.3-2.1$ \\
\hline Tensile test & $142 \pm 9$ & 1.73 \\
\hline Tensile test & - & $0.59 \pm 0.02$ \\
\hline Tensile test & $169.2 \pm 3.5$ & $0.6-1.2$ \\
\hline Tensile test & $164.9 \pm 4$ & - \\
\hline Indentation test & $60-200$ & - \\
\hline Indentation test & 168 & - \\
\hline
\end{tabular}

Table 2. Single-crystal silicon mechanical properties data (Sharpe, 2001)

\begin{tabular}{|c|c|}
\hline Methods & $\begin{array}{c}\text { Young's Modulus } \\
{[\text { GPa] }}\end{array}$ \\
\hline Bulge test & 394 \\
\hline Bulge test & $88 \pm 10-242 \pm 30$ \\
\hline Bulge test & 331 \\
\hline Indentation test & 395 \\
\hline Bending test & $470 \pm 10$ \\
\hline
\end{tabular}

Table 3. Silicon-carbide mechanical properties data (Sharpe, 2001)

\begin{tabular}{|c|c|c|}
\hline Methods & $\begin{array}{c}\text { Young's Modulus } \\
{[\mathrm{GPa}]}\end{array}$ & $\begin{array}{c}\text { Fracture Strength } \\
{[\mathrm{GPa}]}\end{array}$ \\
\hline Resonant test & $130-146 \pm 20 \%$ & - \\
\hline Resonant test & 192 & - \\
\hline Resonant test & $194.25 \pm 1 \%$ & - \\
\hline Bulge test & $230 \& 330$ & - \\
\hline Bulge test & $110 \& 160$ & $0.39-0.42$ \\
\hline Bulge test & $222 \pm 3$ & - \\
\hline Indentation test & $101-251$ & - \\
\hline Indentation test & $216 \pm 10$ & - \\
\hline
\end{tabular}

Table 4. Silicon-nitride mechanical properties data (Sharpe, 2001) 


\begin{tabular}{|c|c|c|}
\hline Methods & $\begin{array}{c}\text { Young's Modulus } \\
{[\mathrm{GPa}]}\end{array}$ & $\begin{array}{c}\text { Fracture Strength } \\
{[\mathrm{GPa}]}\end{array}$ \\
\hline Indentation test & 64 & $>0.6$ \\
\hline Bending test & 83 & - \\
\hline Tensile test & - & $0.6-1.9$ \\
\hline
\end{tabular}

Table 5. Silicon-oxide mechanical properties data (Sharpe, 2001)

\begin{tabular}{|c|c|c|c|c|}
\hline & $\begin{array}{c}\text { Ebulk }_{\text {boung's }} \\
{[G P a]}\end{array}$ & $\begin{array}{c}\text { Youeld } \\
\text { Modulus } \\
\text { [GPa] }\end{array}$ & $\begin{array}{c}\text { Ultimate } \\
\text { Strength } \\
\text { [GPa] }\end{array}$ & $\begin{array}{c}\text { Strength } \\
\text { [GPa] }\end{array}$ \\
\hline Gold & 74 & $98 \pm 4$ & - & - \\
\hline Gold & 74 & 82 & - & $0.33-0.36$ \\
\hline Copper & 117 & $86-137$ & $0.12-0.24$ & $0.33-0.38$ \\
\hline Aluminum & 69 & $8-38$ & - & $0.04-0.31$ \\
\hline Aluminum & 69 & 40 & - & 0.15 \\
\hline Titanium & 110 & $96 \pm 12$ & - & $0.95 \pm 0.15$ \\
\hline
\end{tabular}

Table 6. Metal films mechanical properties data (tensile test) (Sharpe, 2001; Tabata, 2006)

\begin{tabular}{|c|c|c|c|}
\hline & $\begin{array}{c}\text { Young's } \\
\text { Modulus } \\
\text { [GPa] }\end{array}$ & $\begin{array}{c}\text { Yield } \\
\text { Strength } \\
\text { [GPa] }\end{array}$ & $\begin{array}{c}\text { Ultimate } \\
\text { Strength } \\
\text { [GPa] }\end{array}$ \\
\hline $\mathrm{Ni}$ & 202 & 0.4 & 0.78 \\
\hline $\mathrm{Ni}$ & $176 \pm 30$ & $0.32 \pm 0.03$ & 0.55 \\
\hline $\mathrm{Ni}$ & $131-160$ & $0.28-0.44$ & $0.46-0.76$ \\
\hline $\mathrm{Ni}$ & $231 \pm 12$ & $1.55 \pm 0.05$ & $2.47 \pm 0.07$ \\
\hline $\mathrm{Ni}$ & $181 \pm 36$ & $0.33 \pm 0.03$ & $0.44 \pm 0.04$ \\
\hline $\mathrm{Ni}$ & $158 \pm 22$ & $0.32 \pm 0.02$ & $0.52 \pm 0.02$ \\
\hline $\mathrm{Ni}$ & $182 \pm 22$ & $0.42 \pm 0.02$ & $0.60 \pm 0.01$ \\
\hline $\mathrm{Ni}$ & $156 \pm 9$ & $0.44 \pm 0.03$ & - \\
\hline $\mathrm{Ni}$ & $160 \pm 1$ & 0.28 & - \\
\hline $\mathrm{Ni}$ & 194 & - & - \\
\hline $\mathrm{Ni}-\mathrm{Fe}$ & 119 & 0.73 & 1.62 \\
\hline $\mathrm{Ni}-\mathrm{Fe}$ & 155 & - & 2.26 \\
\hline $\mathrm{Ni}-\mathrm{Fe}$ & - & $1.83-2.20$ & $2.26-2.49$ \\
\hline
\end{tabular}

Table 7. Electroplated nickel and nickel-iron mechanical properties data (tensile test) (Sharpe, 2001; Tabata, 2006)

\begin{tabular}{|c|c|c|}
\hline Methods & $\begin{array}{c}\text { Young's Modulus } \\
\text { [GPa] }\end{array}$ & $\begin{array}{c}\text { Fracture Strength } \\
\text { [GPa] }\end{array}$ \\
\hline Bending test & $600-1100$ & $0.8-1.8$ \\
\hline Buckling test & $94-128$ & - \\
\hline Tensile test & - & $8.5 \pm 1.4$ \\
\hline
\end{tabular}

Table 8. Diamond-like carbon mechanical properties data (Sharpe, 2001)

\section{Summary}

The measurement of MEMS materials mechanical properties is crucial for the design and evaluation of MEMS devices. Even though a lot of research has been carried out to evaluate 
the repeatability, accuracy and data reliability of various measurement methods for mechanical properties of MEMS materials, the manufacturing and testing technology for materials used in MEMS is not fully developed. In this chapter an overview of basic test methods and mechanical properties of MEMS materials is given along with definitions of mechanical properties of interest. Also, a summary of the mechanical properties of various MEMS materials is given. Variation of obtained results for common materials may be attributed to the lack of international standards on MEMS materials and their properties measurement methods. It must be pointed out that although MEMS is an area of technology of rapidly increasing economic importance with anticipated significant growth, the ability to develop viable MEMS is to a large degree constrained by the lack of international standards on MEMS materials and their properties measurement methods that would establish fundamentals of reliability evaluation, especially on MEMS material properties.

\section{Acknowledgement}

Authors are grateful for the partial support of the Ministry of Science and Technological Development of Republic of Serbia (contract TP-11014).

\section{References}

Allameh, S.M. (2003). An intorduction to mechanical-properties-related issues in MEMS structures. Journal of materials science, 38, (2003) 4115-4123, ISSN: 1573-4803

Dual, J.; Simons, G.; Villain, J.; Vollmann, J. \& Weippert, C. (2004). Mechanical properties of MEMS structures, Proceedings of ICEM12, ISBN: 88-386-6273-8, Bari, Italy, AugustSeptember 2004, McGraw-Hill

Espinosa, H.D.; Prorok, B.C. \& Fischer, M. (2003). A methodology for determining mechanical properties of freestanding thin films and MEMS materials. Journal of the Mechanics and Physics of Solids, 51, (2003) 47-67, ISSN: 0022-5096

Sharpe, W.N.Jr. (2001). Mechanical Properties of MEMS materials, In: The MEMS Handbook, Mohamed Gad-el-Hak, 3/1- 3/33, CRC Press, ISBN: 978-0849300776, USA

Tabata, O. \& Tsuchiya, T. (2006). Material Properties: Measurement and Data, In: MEMS, A Practical Guide of Design, Analysis, and Applications, Jan Korvink, 53-92, Springer, ISBN: 978-3540211174

Tsuchiya, T. (2008). Evaluation of Mechanical Properties of MEMS Materials and Their Standardization. In: Advanced Micro and Nanosystems, Tabata, O. \& Tsuchiya, T., 125, Wiley-VCH Verlag GmbH \& Co. KgaA, ISBN: 978-3-527-31494-2, Weinheim

Yi, T. \& Kim, C-J. (1999). Measurement of mechanical properties for MEMS materials. Measurement Science and Technology, 10, (1999) 706-716, ISSN: 1361-6501 


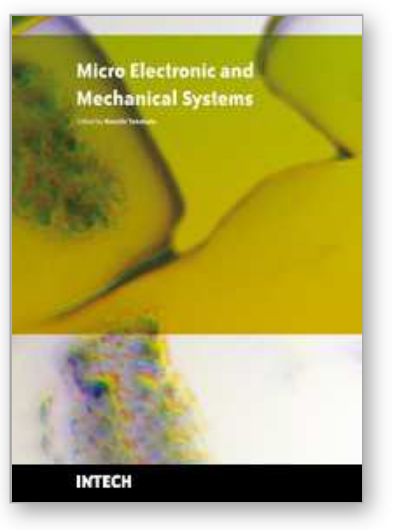

\author{
Micro Electronic and Mechanical Systems \\ Edited by Kenichi Takahata
}

ISBN 978-953-307-027-8

Hard cover, 386 pages

Publisher InTech

Published online 01, December, 2009

Published in print edition December, 2009

This book discusses key aspects of MEMS technology areas, organized in twenty-seven chapters that present the latest research developments in micro electronic and mechanical systems. The book addresses a wide range of fundamental and practical issues related to MEMS, advanced metal-oxide-semiconductor (MOS) and complementary MOS (CMOS) devices, SoC technology, integrated circuit testing and verification, and other important topics in the field. Several chapters cover state-of-the-art microfabrication techniques and materials as enabling technologies for the microsystems. Reliability issues concerning both electronic and mechanical aspects of these devices and systems are also addressed in various chapters.

\title{
How to reference
}

In order to correctly reference this scholarly work, feel free to copy and paste the following:

Zdravko Stanimirović and Ivanka Stanimirović (2009). Mechanical Properties of MEMS Materials, Micro Electronic and Mechanical Systems, Kenichi Takahata (Ed.), ISBN: 978-953-307-027-8, InTech, Available from: http://www.intechopen.com/books/micro-electronic-and-mechanical-systems/mechanical-properties-ofmems-materials

\section{INTECH}

open science | open minds

\section{InTech Europe}

University Campus STeP Ri Slavka Krautzeka 83/A 51000 Rijeka, Croatia Phone: +385 (51) 770447

Fax: +385 (51) 686166 www.intechopen.com

\section{InTech China}

Unit 405, Office Block, Hotel Equatorial Shanghai No.65, Yan An Road (West), Shanghai, 200040, China 中国上海市延安西路65号上海国际贵都大饭店办公楼405单元 Phone: +86-21-62489820

Fax: +86-21-62489821 
(C) 2009 The Author(s). Licensee IntechOpen. This chapter is distributed under the terms of the Creative Commons Attribution-NonCommercialShareAlike-3.0 License, which permits use, distribution and reproduction for non-commercial purposes, provided the original is properly cited and derivative works building on this content are distributed under the same license. 